\title{
Previsão de consumo de água via modelagem matemática de sistema de abastecimento de água
}

\author{
Mathematical model for estimating water consumption
}

\author{
Alexandre André Feil | Claus Haetinger \\ Data de entrada: 18/01/2013 | Data de aprovação: 10/10/2013 \\ DOI: http://dx.doi.org/10.4322/dae.2014.119
}

Resumo

Este estudo objetiva caracterizar o Sistema de Abastecimento de Água da CORSAN de Lajeado/RS no período de 2000 a 2007. O trabalho pretende prever o consumo de água pela população de Lajeado, entre 2008 e 2032, por meio de um modelo matemático aplicado ao SAA da CORSAN a fim de verificar a probabilidade de um colapso por escassez de água. A metodologia utilizada foi a qualitativa para caracterização, tabulação e pareamento dos dados, e a quantitativa na previsão futura através do software LAB Fit Ajuste de Curvas. Concluiu-se que o consumo per capita médio de 2000 a 2007 foi de 143,25 L/hab.dia, e que em 2007 o setor residencial representava 84\% do consumo total. As variáveis intervenientes no consumo per capita correspondem à umidade relativa do ar, taxa média, e população total. A previsão futura detectou uma extrapolação da vazão máxima da água tratada produzida a partir de 2026.

Palavras-chave: Consumo per capita de água. Variáveis intervenientes. Gestão de companhia de água.

\begin{abstract}
The aim of this research is to characterise CORSAN Water Supply System, in Lajeado/RS from 2000 to 2007. This study aims to estimate the total amount of water consumed by the population of Lajeado between 2008 and 2032 by applying a mathematical model to CORSAN Water Supply System so as to determine whether a collapse by water shortage is likely to happen. For characterisation, charting and combination of information, the qualitative methodology was used. The quantitative methodology was used to predict future information through software LAB Fit Curve Fitting. The results show an estimate daily per capita water consumption of 143.25 litres between 2000 and 2007. In addition, they show that home consumption accounted for $84 \%$ of the total consumption in 2007. Intervening variables in per capita consumption correspond to relative humidity, average rate, and the total population. The resulting estimation predictions ascertain an extrapolation in the maximum water supply in 2026.
\end{abstract}

Key-words: Per capita water consumption. Intervening variables. Management of Water Companies.

\footnotetext{
Alexandre André Feil*

Doutorando em Qualidade Ambiental pela Universidade Feevale. Mestre em Ambiente e Desenvolvimento e Graduado em Ciências Contábeis pelo Centro Universitário Univates. Professor no Centro Universitário Univates.

Claus Haetinger

Doutor, mestre e Graduado em Matemática pela Universidade Federal do Rio Grande do Sul - URGS, e Professor do Programa de Mestrado e Doutorado em Ambiente e Desenvolvimento no Centro Universitário Univates.

*Endereço para correspondência: Rua Avelino Tallini, 171 Bairro Universitário, Lajeado - RS, 95900-000, Brasil.

Departamento de Gestão Organizacional - CGO.

Telefone: +5551 3714-7000.

E-mail: alexandre.feil1@gmail.com
} 


\section{Introdução}

É senso comum a ideia de que a água tem extrema importância para a sobrevivência da sociedade. Por este fato, sempre existiu, desde a antiguidade, uma proximidade da localização das civilizações humanas com as margens de rios, lagos e fontes rasas de água, motivada pela procura de fontes de água cada vez mais limpas e inesgotáveis, mesmo havendo grande quantidade disponível por habitante (WOLMAN, 1959).

Atualmente, o planeta dispõe de aproximadamente 1,386 bilhões de $\mathrm{km}^{3}$ de água; destes, $97,5 \%$ representam a água salgada, e 2,5\%, a água doce. Dos 2,5\% de água doce, 99,6\% estão indisponíveis para o consumo humano. A água doce disponível na superfície da Terra para o consumo representa, portanto, apenas $0,4 \%$, encontrada em lagos, zonas úmidas e rios (CLARKE e KING, 2005). Os mesmos autores ainda destacam que essa pequena parcela de água doce disponível, além de mal distribuída, gera diversas crises e guerras.

A escassez de água não é problema somente em países pobres; países mais ricos como Austrália, Espanha, Estados Unidos, Japão e partes do Reino Unido também estão enfrentando problemas de abastecimento de água, provocados pela combinação de mudanças climáticas, com infraestrutura inadequada e má gestão dos recursos hídricos (PITTOCK, 2006). O referido autor ainda destaca que encontrar uma solução para a crise dos recursos hídricos cabe tanto aos países ricos como aos pobres, uma vez que a água necessita ser utilizada com mais eficiência no planeta.

O Brasil, apesar de concentrar $14 \%$ de toda a água potável do mundo, apresenta má distribuição e falta de água devido aos usos múltiplos (navegação, irrigação, abastecimento humano, recreação e turismo, abastecimento industrial, pesca e aquicultura, hidroeletricidade, entre outros) e à densidade demográfica (TUNDISI, 2008).

A densidade demográfica brasileira, em 2007, foi de 22,3 hab/ $\mathrm{km}^{2}$; a do estado do Rio Grande do Sul foi de $37,56 \mathrm{hab} / \mathrm{km}^{2}$; e da cidade de Lajeado/RS atingiu $746,39 \mathrm{hab} / \mathrm{km}^{2}$, o que corresponde a uma média 19,89 vezes maior em relação ao próprio estado (IBGE, 2008). Destaca-se que Lajeado é uma das cidades mais densamente povoadas do estado do Rio Grande do Sul, pois é essencialmente urbana, com um percentual de 97\%, especialmente a partir das emancipações dos últimos distritos, no ano 2000 (PML, 2009). Desta forma, Lajeado exige maior demanda urbana de água por hab $/ \mathrm{km}^{2}$.

Nesta lógica, o tema deste estudo é a previsão do consumo de água, tendo como objetivo geral caracterizar o Sistema de Abastecimento de Âgua (SAA) da Companhia Riograndense de Saneamento (CORSAN) e realizar, via modelagem matemática, uma previsão de consumo de água em função de variáveis, do município de Lajeado/ RS. Os objetivos específicos são: a) caracterizar o volume de água bruta captada, a água tratada produzida, a água consumida, a perda de água, a população total, a população abastecida e não abastecida, a extensão da rede de distribuição e a quantidade de ligações totais; b) identificar o consumo per capita médio de água (L/hab.dia) e os percentuais de consumo per capita em cada um dos setores (residencial, comercial, público e industrial) no ano de 2007; c) identificar as variáveis intervenientes que influenciam no consumo per capita de água; d) obter uma previsão do crescimento da captação, tratamento e do consumo de água, através da modelagem matemática de 2008 a 2032.

A importância deste estudo para a CORSAN de Lajeado consiste no auxílio ao sistema de abastecimento de água, em gerir a demanda de água e estipular uma linha de tendência que determine a possibilidade de ocorrência de falta de água em consequência do crescimento populacional.

A problemática deste estudo surgiu pela falta de projetos e pesquisas nesta linha de informação no Vale do Taquari (onde fica localizada a CORSAN), região fortemente dependente do rio Taquari para abastecimento do consumo de água do município de Lajeado. Considerando-se o crescimento populacional, a limitação da oferta de água e o aumento da demanda de água por habitante no município, especialmente a partir das emancipações dos seus últimos distritos, levantou-se o questionamento acerca da possibilidade, ou não, de um colapso por falta de água, caso sejam mantidas a mesma vazão e infraestrutura do ano de 2007.

\section{Referencial teórico}

Segundo Nucci (1983) e Narchi (1989), a demanda urbana de água corresponde à quantidade total de água necessária para as diversas intenções de utilização em uma área demarcada, sendo um fator importante para o planejamento 
e gestão de SAA, mas, para isso, deve haver um histórico de registro de dados a serem pareados em forma de série temporal para serem analisados posteriormente (NARCHI, 1989).

Essas séries temporais, segundo Trautwein (2004), consistem em um conjunto de observações de variáveis feitas de forma sequencial ao longo de um tempo, sendo os dados coletados dependentes entre si. O autor complementa ainda que o método de previsão é um processo através do qual as séries temporais são combinadas estatisticamente para determinar estimativas sobre o futuro.

No Brasil, o método de previsão não está sendo usado em larga escala. Geralmente, o SAA é planejado a partir da previsão e projeção do consumo per capita de água. Embora seja um dos principais fatores de projeção, não pode ser o único, uma vez que há variações de fatores externos (ROCHA e SILVA, 1999).

Von Sperling (1996) denomina de consumo per capita o consumo médio de água por dia de um indivíduo, e essa água demandada pelos indivíduos se expressa em litros por habitante por dia (L/hab.dia). Em revisões bibliográficas, o mesmo autor determinou valores típicos de consumo per capita de água (Tabela 1), que são utilizados como parâmetros para avaliação de SAA.

\begin{tabular}{l|c|c|}
\multicolumn{1}{c|}{ Porte } & $\begin{array}{c}\text { Habitantes por } \\
\text { Faixa }\end{array}$ & $\begin{array}{c}\text { Consumo per capita } \\
\text { (L/hab.dia) }\end{array}$ \\
\hline Povoado Rural & $<5.000$ & $90-140$ \\
\hline Vila & $5.000-10.000$ & $100-160$ \\
\hline $\begin{array}{l}\text { Pequena } \\
\text { Localidade }\end{array}$ & $10.000-50.000$ & $110-180$ \\
\hline Cidade Média & $50.000-250.000$ & $120-220$ \\
\hline Cidade Grande & $>250.000$ & $150-300$ \\
\hline
\end{tabular}

Fonte: Von Sperling (1996, p. 52).

Tabela 1 - Valores típicos de consumo per capita de água.

Silva et al. (2008), em estudo realizado na cidade de Cuiabá com dados históricos de 2000 a 2006, identificaram que o consumo médio per capita de água nessa cidade representava $175 \mathrm{~L} /$ hab.dia, e destacaram que este consumo per capita corrobora com os valores típicos da Tabela 1. Eles ainda descrevem que não encontraram interferências climáticas na determinação do consumo per capita de água, divergindo, neste aspecto, da literatura clássica que relata a exis- tência dessa influência.

Magalhães et al. (2001), que estudaram 83 SAA rurais e urbanos em São Paulo, com população de até 113 mil habitantes, concluíram que há fraca influência da relação entre o porte da cidade e o consumo per capita de água. Neste sentido, elaboraram a Tabela 2, que contém as faixas de população e seus respectivos consumos per capita, e perceberem que o valor do consumo per capita de água não variou de forma significativa, em relação ao aumento da faixa de população.

\begin{tabular}{|c|c|}
\hline $\begin{array}{c}\text { Faixa de população } \\
\text { (habitantes) }\end{array}$ & $\begin{array}{c}\text { Consumo per capita } \\
\text { L/hab.dia) }\end{array}$ \\
\hline$<2.000$ & 130 \\
\hline $2.000-10.000$ & 125 \\
\hline $10.000-50.000$ & 133 \\
\hline $50.000-120.000$ & 128 \\
\hline
\end{tabular}

Fonte: Magalhães et al. (2001, p. 3).

Tabela 2 - População versus consumo per capita.

Em estudo realizado no município de Botucatu/SP, no ano de 1995, com uma população de 102.395 habitantes, Herrera (1996) concluiu que o consumo per capita naquele ano foi de 164,87 L/hab.dia. Portanto, o valor per capita nesse estudo se enquadra nos valores típicos da Tabela 1, mas difere da Tabela 2 . 0 estudo realizado por Ayres (2000), no município de Dourados/MS em 1999, com uma população de 164.716 habitantes, conclui que o consumo per capita nesse ano foi de 106 L/hab.dia. Neste caso, o consumo per capita não se enquadra nos valores típicos da Tabela 1 nem em relação à Tabela 2. Neste sentido, nem todos os consumos per capita se enquadram dentro do porte de valores da Tabela 1 ou da Tabela 2, ou seja, existem variáveis específicas em cada região que interferem no consumo per capita de água (MAGALHÃES et al., 2001).

As principais variáveis intervenientes no consumo residencial de água elencados pela literatura técnica de Foster et al. (1979 apud AMARAL e SHIROTA, 2000), Von Sperling et al. (2002), Trautwein (2004), Fernandes Neto (2003), Fernandes Neto et al. (2004), Falkenberg (2005), Silva (2008) e Dias et al. (2010) são as seguintes: o clima, o percentual de hidrometração, a qualidade da água, a pressão da rede de distribuição, o valor médio da tarifa de água, o nível socioeconômico, os erros de leitura dos hidrômetros, 
a população, a extensão da rede de distribuição, entre outros.

\section{Distribuição do consumo por setores}

Quanto à caracterização dos setores consumidores de água, na cidade de Botucatu/SP, entre 1990 e 1995, Herrera (1996) concluiu que $76 \%$ do consumo total de água correspondiam ao setor residencial; $11 \%$, ao setor comercial; $10 \%$, ao setor outros (público); $3 \%$, ao setor industrial. Ayres (2000), com base na cidade de Dourados/MS, no período entre 1998 e 1999, concluiu que $90,96 \%$ do consumo total de água correspondiam ao setor residencial; 5,58\%, ao setor comercial; $3,35 \%$, ao setor público; $0,11 \%$, ao setor industrial. Portanto, nota-se em relação a esses estudos que o maior consumo de água está relacionado ao setor residencial, e o menor, ao industrial.

O fato de esses estudos nas cidades de Botucatu/SP e Dourados/MS, assim como os rios Sorocaba e Médio Tietê/SP (que abrangem a cidade de Botucatu), a Bacia do Rio Tietê e o Estado de São Paulo (Tabela 3) apresentarem maior consumo de água no setor residencial (urbano) não pode ser instituído como regra, pois, analisando-se a Tabela 3, nota-se resultados diferentes quanto à maior demanda de água nos diversos setores. Na demanda hídrica da Bacia Hidrográfica Baixo Tiete/SP é o setor industrial quem lidera, em seguida vem o urbano e, logo após, irrigação. Na Bacia Hidrográfica do rio Tiete/Jacaré/SP a maior demanda de água é representada pela irrigação, e após seguem a industrial e a urbana (SÃO PAULO, 2007). Diante dessas informações, percebe-se que depende das características específicas de cada região na determinação de existir maior ou menor demanda de água para um ou outro setor de consumo.
É relevante destacar que a demanda do rio Ivinhema/MS (Tabela 4) que abrange a cidade de Dourados/MS, estudo de Ayres (2000), apresenta o consumo animal como líder e em seguida a irrigação, urbana e industrial. Desta forma, também não há evidências para determinar que o maior consumo seja o residencial. Fortalecendo esta lógica, pode-se analisar o rio Pardo/MS, que apresenta como maior consumo o urbano e em seguida o animal, industrial e a irrigação; e, quando analisadas as Bacias Hidrográficas totais do estado do MS nota-se que o consumo de água animal aparece em primeiro lugar e em seguida o urbano, irrigação e o industrial (PERH-MS, 2010).

Para Tundisi (2008), em função das altas demandas de produção de alimentos na maioria dos países ou regiões específicas, o consumo de água na agricultura (animal, irrigação, entre outros) representa $70 \%$ da disponibilidade total de água, e acrescenta que há uma excessiva utilização de águas subterrâneas para a irrigação. Queiroz e Oliveira (2013) também destacam que a agricultura é o maior demandante de água, e na sequência o abastecimento público e o abastecimento industrial.

\section{Modelagem Matemática}

A utilização da modelagem matemática na gestão hídrica é uma ferramenta útil para auxiliar na expansão e na regulação do fornecimento de água, assumindo o contexto local como base para previsão e otimização na demanda de água (SILVA et al., 2008).

A previsão de valores em longo prazo é menos suscetível à variação do consumo, além disso, ao longo do tempo, pode ser ajustada, introduzindo-se os dados observados para adaptá-los aos projetados (ROCHA e SILVA, 1999).

\begin{tabular}{l|c|c|l|l|} 
& \multicolumn{4}{|c|}{ Demanda Hídrica (\%) } \\
\hline Rios e Bacias & Urbano & Industrial & Irrigação & Outros \\
\hline Rios Sorocaba e Médio Tietê & 33,70 & 27,16 & 29,45 & 9,69 \\
\hline Rio Baixo Tietê & 24,83 & 48,71 & 19,40 & 7,07 \\
\hline Rios Tiete/Jacaré & 19,14 & 31,60 & 38,78 & 10,49 \\
\hline Bacia Hidrográfica do Rio Tietê & 41,53 & 32,81 & 16,35 & 9,69 \\
\hline Estado de São Paulo & 32,10 & 29,43 & 27,37 & 11,11 \\
\hline
\end{tabular}

Fonte: São Paulo (2007).

Tabela 3 - Demanda hídrica na Bacia Hidrográfica do Rio Tietê/SP. 


\begin{tabular}{l|c|c|c|c|c|} 
& \multicolumn{4}{|c|}{ Demanda Hídrica (\%) } & \\
\hline Rios & Urbano & Industrial & Irrigação & Animal & Outros \\
\hline Ivinhema & 22,41 & 6,90 & 24,14 & 43,10 & 3,45 \\
\hline Pardo & 37,31 & 19,40 & 5,97 & 35,82 & 1,49 \\
\hline Total do MS & 19,61 & 6,54 & 16,34 & 55,56 & 1,96 \\
\hline
\end{tabular}

Fonte: PERH-MS (2010)

Tabela 4 - Demanda hídrica da região hidrográfica do Paraná/MS dos rios Ivinhema e Pardo.

A previsão é o método que parte de séries temporais, sendo os dados combinados estatisticamente para determinar uma estimativa futura (TRAUTWEIN, 2004). Complementando, Makridakis (1998 apud TRAUTWEIN, 2004), ao analisar a ciência da previsão, observa que a eficiência dela depende do número de períodos a serem cobertos no futuro pela mesma, pois, à medida que o horizonte da previsão aumenta, os resultados tornam-se mais vulneráveis a erros ou incertezas. Este método de previsão pode ser realizado via modelagem matemática que, segundo Bassanezi (2006), enquanto arte de transformar uma posição da realidade atual em problema matemático busca encontrar funções e soluções numa linguagem usual, com a utilização de softwares, pois as funções resultantes são complexas.

Atualmente há dezenas de softwares que lidam com modelagem matemática. Um dos que se destacam no Brasil é o software LAB Fit Ajuste de Curvas por seu amplo uso no ensino e nos laboratórios de pesquisa e por fornecer certificados de programas estatísticos do Statistical Reference Datasets Project (SRDP) do National Institute of Standards and Technology (NIST) (SILVA et al., 2004).

O software LAB Fit Ajuste de Curvas 7.2.31 (SILVA et al., 2004) foi desenvolvido para analisar e trabalhar com dados em larga escala, uma vez que tem aspectos de ajuste de uma função com sua representação gráfica. Além disso, contém um menu com cálculos estatísticos básicos e outro com cálculos de programação de erros, além de uma biblioteca de mais de 200 funções com uma variável independente e 280 funções com duas variáveis independentes previamente definidas. Estes autores acrescentam que as funções são classificadas conforme valor mais baixo do qui-quadrado $\left(\mathrm{x}^{2}\right)$, qui-quadrado reduzido $\left(\mathrm{x}^{2}\right.$ red.), o qual fornece o coeficiente de correlação $(r)$, o coeficiente de determinação $\left(r^{2}\right)$ e os graus de liberdade (gl).

$\mathrm{O}$ teste de $\mathrm{x}^{2}$ e $\mathrm{x}^{2}$ red. utilizados como parâmetros pelo software LAB Fit Ajuste de Curvas para classificar as funções corresponde a uma avaliação da discrepância entre as frequências dos dados observados e esperados (WITTE e WITTE, 2005). Segundo Levine et al. (2005), se, por um lado, as diferenças forem pequenas ou insignificantes, mas suficientes para serem consideradas comuns, a hipótese nula é considerada aceitável ou verdadeira. Se, por outro lado, as diferenças forem suficientemente grandes para serem consideradas como resultado raro, a hipótese nula não é considerada aceitável ou rejeitada.

O valor do nível de significância, resultante da discrepância entre as frequências observadas e esperadas, é o percentual de chances de uma série temporal se enquadrar numa região de não rejeição; ou seja, se o nível de significância for 0,05 , as chances de uma série temporal se enquadrar na região de não rejeição ou aceitável é de $95 \%$ e as chances de se enquadrar numa região de rejeição ou inaceitável é de 5\% (LEVINE et al., 2005).

A localização do valor de $\mathrm{x}^{2}$ crítico está ligada ao conhecimento dos Graus de Liberdade (gl). Os gl de uma variável são sempre o número total de categorias $(\mathrm{x}, \mathrm{y})$ menos 1 ; e os gl de duas variáveis são o número de categorias menos o 1. Este resultado é multiplicado pelo valor resultante do número total de categorias (séries temporais) menos 1 (WITTE e WITTE, 2005).

Outro parâmetro estatístico fornecido pelo software LAB Fit Ajuste de Curvas é que o coeficiente de correlação (r) é aquele que mede o grau de dependência, isto é, descreve a relação linear entre pares de dados em séries temporais quantitativas (WITTE e WITTE, 2005). Webster (2006) acrescenta que é uma medida de precisão de ajuste, ou seja, uma medida de confiabilidade em que o modelo da reta se ajusta aos dados 
coletados. O coeficiente de correlação pode assumir qualquer valor entre -1 e 1; quando o valor é $\mathrm{r}=1$, há correlação positiva perfeita. Caso contrário, o valor do coeficiente de correlação é $\mathrm{r}=-1$, quando há correlação negativa perfeita (CALLEGARI-JAQUES, 2003).

Já o coeficiente de determinação de Pearson $\left(\mathrm{r}^{2}\right)$, também fornecido pelo software LAB Fit Ajuste de Curvas, é definido como índice de variação em que uma variável é explicada em função da outra (WEBSTER, 2006). A variação do coeficiente de determinação vai de 0 a 1 . Quanto maior o valor de $\mathrm{r}^{2}$, melhor a função combina com o gráfico de dispersão (MOTTA, 2006).

Após definir o conceito e a variação do coeficiente de correlação, também é importante destacar que a variação é medida pela intensidade entre duas variáveis que foram descritos na Tabela 5, conforme Callegari-Jaques (2003).

\begin{tabular}{c|c|}
\hline$r$ & A correlação é dita \\
\hline 0 & Nula \\
\hline $0-0,3$ & Fraca \\
\hline $0,3 \mathrm{I}-0,6$ & Regular \\
\hline $0,6 \mathrm{I}-0,9$ & Forte \\
\hline $0,9 \mathrm{I}-1$ & Muito forte \\
\hline 1 & Plena ou perfeita \\
\hline
\end{tabular}

Fonte: Callegari-Jaques (2003, p. 90).

Tabela 5 - Avaliação qualitativa quanto à intensidade da correlação entre duas variáveis.

\section{Metodologia}

A área deste estudo localiza-se na parte centro-leste do estado do Rio Grande do Sul (Figura 1a), na região denominada Vale do Taquari (Figura 1b), na área municipal de Lajeado (PML, 2009).

A água bruta para fins de tratamento e abastecimento é captada no Rio Taquari e conduzida à Estação de Tratamento de Água (ETA), onde passa pelos processos de floculação, decantação, filtração, cloração, fluoretação e laboratório (que processa análises e exames físico-químicos e bacteriológicos). Depois ocorre o bombeamento da água tratada para os reservatórios e, por fim, sua distribuição por canalizações às residências (CORSAN, 2009).

A área total de Lajeado é de $90,40 \mathrm{~km}^{2}$ (PML, 2009). Entretanto, bairros como Planalto, Igrejinha, Centenário, Imigrante, Conventos, São Bento e Floresta (SNIS, 2009) não são atendidos

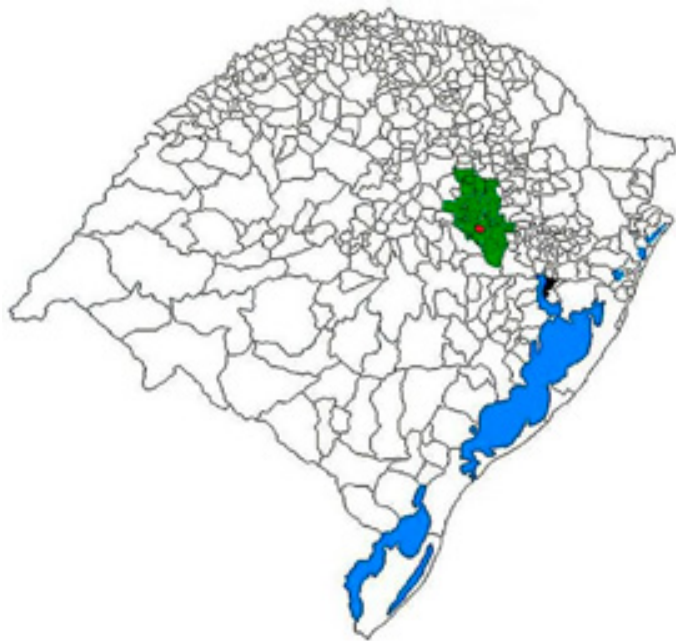

Fonte: Adaptado de PML (2009)

Figura 1a - Localização geográfica da cidade de Lajeado no estado do Rio Grande do Sul.

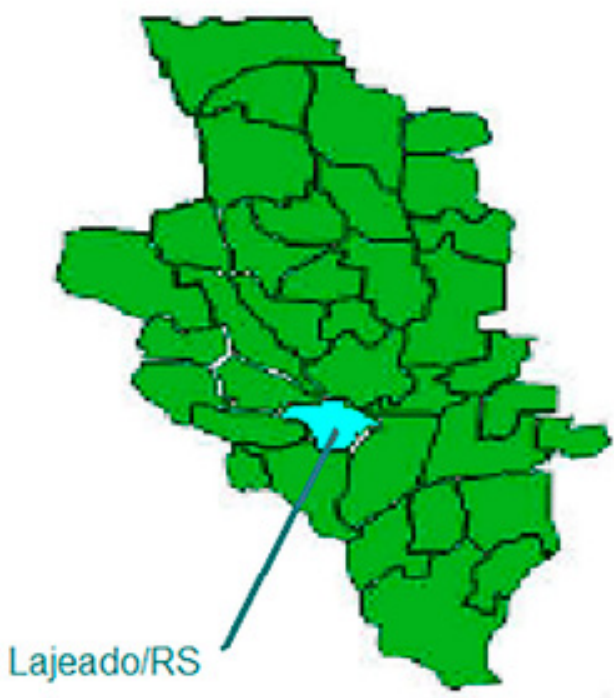

Fonte: Adaptado de BDR (2009).

Figura 1 - Localização do município de Lajeado na região do Vale do Taquari/RS.

pela CORSAN.

Este estudo restringe-se aos bairros abastecidos com a infraestrutura da sede da CORSAN, no período de 2000 a 2007, e não será considerada a qualidade da água, nem o comportamento sociológico da população em relação ao consumo doméstico de água.

O volume médio da vazão de água bruta captada no ano de 2007 utilizada para abastecer a demanda do volume de consumo foi de $0,245 \mathrm{~m}^{3}$ por segundo, e o volume máximo da vazão era de 
$0,365 \mathrm{~m}^{3}$ por segundo. Transformando o volume médio da vazão de $\mathrm{m}^{3}$ por segundo $\mathrm{em}^{3}$ anuais tem-se um volume de 6,3 milhões de $\mathrm{m}^{3}$ /ano, e no caso da vazão máxima tem-se 9,3 milhões de $\mathrm{m}^{3}$ /ano, considerando a estrutura física atual da ETA (CORSAN, 2009).

A coleta de dados referentes ao SAA relativos ao volume anual de água bruta captada e ao volume anual de água tratada produzida foi realizada pelo SNIS (2009), de 2000 a 2007. Os dados coletados no SAA da CORSAN em Lajeado, de 2000 a 2007, equivalem ao volume de água consumida, bem como à participação do volume de água por cada setor de consumo.

Os dados coletados referentes à população (habitantes) foram obtidos no IBGE (2008), com relação ao período de 2000 a 2007, e representam a população total. Os dados obtidos do SNIS (2009) de 2000 a 2007 configuram a população atendida e a população não atendida pelo SAA da CORSAN.

Foram coletados no CIH (2009) os dados referentes às variáveis intervenientes, tais como: Umidade Relativa do Ar Média Anual e Temperatura Média Anual, relativos ao período de 2003 a 2006; Precipitação Pluviométrica ( $\mathrm{mm} / \mathrm{ano})$ e Tarifa Média Anual de Água, referentes ao período de 2003 a 2007. Todos os dados referem-se à cidade de Lajeado/RS, e cabe ressaltar que estes não coincidem com o escopo temporal de 2000 a 2007, pois há indisponibilidade de informações no Centro de Informações Hidrometeorológicos $(\mathrm{CIH})$, neste caso houve uma redução do período da série temporal. Diante da necessidade de se trabalhar com dados pareados entre variáveis, foi preciso reduzir o período das amostras, nestes casos, na etapa da caracterização. $\mathrm{Na}$ etapa da previsão as variáveis intervenientes não foram utilizadas devido à redução do período da amostra.

Após a coleta desses dados, os mesmos foram tabulados e apresentados em forma de tabelas; de um lado, o valor da variável independente $(x)$ que será composto pelos anos; e do outro, o valor da variável dependente (y), que será composto pelo valor dos dados coletados (CORSAN, 2009), (IBGE, 2008) e (SNIS, 2009).

Na etapa de caracterização do SAA da CORSAN de Lajeado/RS será utilizado o software BioEstat 5.0 para determinar o coeficiente de correlação e o coeficiente de determinação. Na etapa da previsão, será utilizado o software LAB Fit Ajuste de Curvas. Após efetuar as previsões das séries temporais coletadas, este software apresenta os melhores valores dessa previsão para os coeficientes de correlação e determinação. Por último, será efetuada uma projeção futura, a fim de verificar se haverá ou não colapso por escassez de água.

Os resultados e as discussões estão destacados por partes separadas, na primeira será apresentada a etapa da caracterização do SAA, logo após será apresentada a etapa de previsão dos dados apurados na etapa da caracterização.

\section{Resultados e discussões: etapa da carac- terização}

A população total de Lajeado/RS (Tabela 6) apresentou, de 2000 a 2001, um decréscimo de $4,77 \%$ devido à emancipação dos distritos per-

\begin{tabular}{c|c|c|c|} 
Tempo (anos) & $\begin{array}{c}\text { População Total } \\
\text { (habitantes) }\end{array}$ & $\begin{array}{c}\text { População Atendida } \\
\text { (habitantes) }\end{array}$ & $\begin{array}{c}\text { População não Atendida } \\
\text { (habitantes) }\end{array}$ \\
\hline 2000 & 64.133 & 49.272 & 14.861 \\
\hline 2001 & 61.072 & 50.964 & 10.108 \\
\hline 2002 & 62.023 & 53.312 & 8.711 \\
\hline 2003 & 63.045 & 54.128 & 8.917 \\
\hline 2004 & 65.190 & 55.776 & 9.414 \\
\hline 2005 & 66.378 & 56.890 & 9.488 \\
\hline 2006 & 66.900 & 54.394 & 12.506 \\
\hline 2007 & 67.474 & 56.151 & 11.323 \\
\hline Crescimento (\%) & 5,21 & 13,96 & $-23,80$ \\
\hline
\end{tabular}

Fonte: Adaptada de IBGE (2009) e SNIS (2009).

Tabela 6 - Série temporal da População (total, atendida e não atendida) pelo SAA da CORSAN de Lajeado/RS. 
tencentes à cidade. A partir das emancipações de seus distritos, Lajeado apresenta uma área urbana de $97 \%$, e área rural de 3\%. O crescimento da população total, no período de 2000 a 2007 , do município é de $5,21 \%$ e a população abastecida pelo SAA da CORSAN de Lajeado/RS cresceu $13,96 \%$. Portanto, percebeu-se que o crescimento da população abastecida foi maior que o crescimento da população total.

A população não abastecida, desse mesmo SAA e período, decresceram $23,80 \%$. Portanto, o crescimento da população atendida foi maior que o crescimento da população total e o decréscimo da população não atendida foi superior ao crescimento da população atendida. Nesta lógica, vale destacar que, na cidade de Lajeado, além do SAA da CORSAN existem outras redes de distribuição particulares de água.

A água bruta captada (Tabela 7), embora tenha apresentado um crescimento de $16,29 \%$, no período de 2000 a 2007, é um resultado que representa um crescimento médio anual inferior, quando comparado com o de Herrera (1996) da cidade de Botucatu/SP (70,5\%) de 1980 a 1995 e o de Ayres (2000) da cidade de Dourados/MS $(43,56 \%)$ de 1990 a 1999.

O crescimento do volume de água tratada produzida de 2000 a 2007 (Tabela 7) foi de $23,96 \%$, e a diferença entre o volume de água bruta captada e de água tratada produzida é a água utilizada para limpeza da ETA (lavagem dos filtros, tubulações e equipamentos). Ao comparar o crescimento do volume de água bruta captada $(16,46 \%)$ e a água tratada produzida (23,96\%), verificou-se maior eficiência no tratamento de água e limpeza da ETA, pois o crescimento do volume de água tratada produzida foi maior em relação ao crescimento do volume de água bruta captada.

Essa diminuição da diferença entre o volume de água bruta captada e o de água tratada produzida (utilizada na limpeza da ETA) é menor a cada ano, pois, por um lado, este último foi colocado à disposição para o consumo e, por outro, como o volume da diminuição da diferença foi consumido, os custos de tratamento e da adução dessa água não tiveram a necessidade de serem revertidos em despesas, caso esse volume de água tivesse sido retornado ao leito do rio Taquari. No estudo de Herrera (1996) a água utilizada na limpeza da ETA volta ao processo de tratamento e após inclui o volume de água tratada produzida.

As perdas na distribuição de água ocorrem entre a água armazenada nos reservatórios da ETA e o volume de água consumida. No período de 2000 a 2007 as perdas tiveram um crescimento de 29,10\% (Tabela 7), e a média de perdas nesse mesmo período foi de $43,75 \%$. Sendo assim, percebeu-se que o fato de o volume de água tratada produzida ser maior que o volume de água consumida decorre em função do aumento das perdas. Portanto, ao passo que as perdas aumentam, o volume de água tratada produzida necessita crescer num mesmo percentual para suprir o volume de água consumida.

A extensão da rede de distribuição de água foi ampliada em 8,53\% (20 Km) de 2001 a 2007, e a quantidade de ligações totais de água cresceu

\begin{tabular}{c|c|c|c|c|c|c|c|}
$\begin{array}{c}\text { Tempo } \\
(\text { anos })\end{array}$ & $\begin{array}{c}\text { Água Bruta } \\
\text { Captada }\left(\mathrm{m}^{3}\right)\end{array}$ & $\begin{array}{c}\text { Água Tratada } \\
\text { Produzida }\left(\mathrm{m}^{3}\right)\end{array}$ & $\begin{array}{c}\text { Consumo } \\
\left(\mathrm{m}^{3}\right)\end{array}$ & $\begin{array}{c}\text { Perdas } \\
\left(\mathrm{m}^{3}\right)\end{array}$ & $\begin{array}{c}\text { Perdas } \\
(\%)\end{array}$ & $\begin{array}{c}\text { Extensão da malha } \\
\text { de distribuição }(\mathrm{m})\end{array}$ & $\begin{array}{c}\text { Ligações } \\
(\text { número })\end{array}$ \\
\hline 2000 & 4.970 .895 & 4.357 .764 & 2.589 .335 & 1.768 .429 & 40,6 & -- & -- \\
\hline 2001 & 4.610 .000 & 4.319 .000 & 2.651 .137 & 1.667 .863 & 38,6 & 233.000 & 12.175 \\
\hline 2002 & 5.073 .000 & 4.722 .000 & 2.619 .012 & 2.102 .988 & 44,5 & 237.000 & 12.520 \\
\hline 2003 & 5.538 .000 & 5.033 .000 & 2.760 .540 & 2.272 .460 & 45,2 & 237.000 & 12.830 \\
\hline 2004 & 5.822 .000 & 5.392 .000 & 2.814 .275 & 2.577 .725 & 47,8 & 237.000 & 13.150 \\
\hline 2005 & 5.796 .000 & 5.336 .000 & 2.918 .871 & 2.417 .129 & 45,3 & 237.000 & 13.431 \\
\hline 2006 & 5.965 .000 & 5.590 .000 & 3.033 .143 & 2.556 .857 & 45,7 & 238.000 & 14.150 \\
\hline 2007 & 5.781 .000 & 5.402 .000 & 3.118 .841 & 2.283 .159 & 42,3 & 253.000 & 14.655 \\
\hline$(\%)^{*}$ & 16,29 & 23,96 & 20,45 & 29,10 & 43,75 & 8,53 & 20,36 \\
\hline
\end{tabular}

Fonte: *Crescimento (\%)

Tabela 7 - Série temporal da água captada, tratada, consumida e perdida, a extensão da rede e o número de ligações. 
20,36\% (2.480 ligações), de 2001 a 2007.

$\mathrm{Na}$ análise do consumo per capita (Tabela 8) do SAA da CORSAN de Lajeado/RS observou-se um crescimento de 5,55\% no período de 2000 a 2007.

\begin{tabular}{|c|c|}
\hline Tempo (anos) & Consumo per capita (L/hab.dia) \\
\hline 2000 & 144 \\
\hline 2001 & 143 \\
\hline 2002 & 135 \\
\hline 2003 & 140 \\
\hline 2004 & 138 \\
\hline 2005 & 141 \\
\hline 2006 & 153 \\
\hline 2007 & 152 \\
\hline Média & 143,25 \\
\hline Crescimento (\%) & 5,55 \\
\hline
\end{tabular}

Tabela 8 - Consumo per capita do SAA da CORSAN de Lajeado/RS.

Observou-se também que o consumo per capita em 2007 representou 152 L/hab.dia. Comparando-se esse consumo com o do estado do Rio Grande do Sul, no mesmo ano, que foi de $169 \mathrm{~L} /$ hab.dia, percebeu-se que existe uma semelhança entre os dois consumos per capita.

$\mathrm{Na}$ comparação do consumo per capita de água da Tabela 8 com os valores típicos de Von Sperling (1996), Tabela 1, notou-se que há uma aderência quanto ao porte da cidade e o consumo per capita, e quando comparado com os valores típicos de Magalhães et al. (2001), Tabela 2, notou-se que o consumo per capita do SAA da CORSAN de Lajeado/RS é consideravelmente maior, observando a mesma faixa de população.

Na decomposição do consumo per capita por setores do ano de 2007, notou-se que o setor residencial apresentou um consumo de $127 \mathrm{~L} /$ hab.dia, representando $84 \%$ do consumo per capita de 2007 (Tabela 8) sendo, consequentemente, o maior consumidor de água. Na sequência, destacou-se o setor comercial com 20 L/hab.dia e representando $13 \%$; em seguida o setor público com $3 \mathrm{~L} /$ hab.dia representando 2\%; e, por último, o setor industrial com $2 \mathrm{~L} /$ hab.dia representando $1 \%$. A representativi- dade elevada do setor residencial no consumo per capita de água é devido à característica da cidade de Lajeado/RS ser essencialmente urbana e suas indústrias possuírem poços particulares para captação de água.

\begin{tabular}{c|c|c|}
$\begin{array}{c}\text { Consumo por } \\
\text { setor }\end{array}$ & Participação (\%) & $\begin{array}{l}\text { Consumo per Capita } \\
\text { (L/hab.dia) }\end{array}$ \\
\hline Residencial & 84 & 127 \\
\hline Comercial & 13 & 20 \\
\hline Público & 2 & 3 \\
\hline Industrial & 1 & 2 \\
\hline Total & 100 & 152 \\
\hline
\end{tabular}

*Apenas foi segregado o ano de 2007 frente ao consumo de água pela participação em cada um dos setores, pela indisponibilidade de informações dos anos de 2000 a 2006.

Tabela 9 - Consumo per capita de água segregado por setor do ano de 2007*.

Em relação ao consumo per capita de água por setor (Tabela 9), verifica-se que o de maior consumo é o residencial, que, em Lajeado/RS, corresponde a $84 \%$. Comparando-se esses percentuais com os obtidos por Herrera (1996) em Botucatu/SP, 76\%, e com os de Ayres (2000) em Dourados/MS, 90,96\%, percebe-se que há semelhança no comportamento desses percentuais, o que se explica pelo fato de o SAA dos três estudos corresponderem a áreas de abastecimento unicamente urbanas, onde, de fato, existe um maior número de economias residenciais.

O setor industrial (Tabela 9) apresentou o menor percentual do consumo total de água: em Lajeado/RS, 1\%; em Botucatu/SP, 3\% (HERRERA, 1996); e em Dourados, 0,11\% (AYRES, 2000). Verifica-se que há similaridade entres os percentuais do consumo total de água no setor industrial nessas cidades. O baixo índice de consumo no setor industrial decorre do fato de a maioria não utilizar água nos processos produtivos, e, as que utilizam, captam-na de poços particulares.

Na sequência, foram apresentadas as variáveis intervenientes na Tabela 10.

A relação entre as variáveis estão representadas na Tabela 11, como também o coeficiente de correlação ( $r$ ), o coeficiente de determinação $\left(\mathrm{r}^{2}\right)$ e o grau de correlação, de acordo com a Tabela 5 de Callegari-Jaques (2003). 


\begin{tabular}{c|c|c|c|c|}
$\begin{array}{c}\text { Tempo } \\
(\text { anos) }\end{array}$ & $\begin{array}{c}\text { Temperatura } \\
\text { Média Anual }\left({ }^{\circ} \mathrm{C}\right)\end{array}$ & $\begin{array}{c}\text { Precipitação } \\
\text { Pluviométrica Anual }(\mathrm{mm})\end{array}$ & $\begin{array}{c}\text { Umidade } \\
\text { Relativa do Ar Média Anual (\%) }\end{array}$ & $\begin{array}{c}\text { Taxa Média } \\
\text { de Água Anual (R\$) }\end{array}$ \\
\hline 2003 & 20,2 & $1.856,6$ & 76 & 3,63 \\
\hline 2004 & 20,0 & $1.038,4$ & 73 & 4,05 \\
\hline 2005 & 20,4 & $1.404,9$ & 76 & 4,31 \\
\hline 2006 & 20,3 & $1.229,9$ & 78 & 4,49 \\
\hline 2007 & -- & $1.720,7$ & -- & 3,98 \\
\hline
\end{tabular}

Fonte: $\mathrm{CIH}$ (2009)

Tabela 10 - Variáveis intervenientes do SAA da CORSAN de Lajeado/RS.

\begin{tabular}{l|c|c|c|}
\multicolumn{1}{c|}{ Relação entre variáveis intervenientes } & $r$ & $r^{2}$ & Grau de correlação \\
\hline Umidade relativa do ar média anual x Consumo per capita* & 0,83 & 0,70 & Forte \\
\hline Taxa média de água anual x Consumo per capita** & 0,64 & 0,41 & Forte \\
\hline População Total x Consumo per capita*** & 0,64 & 0,41 & Forte \\
\hline Temperatura Média Anual x Consumo per capita* & 0,46 & 0,21 & Regular \\
\hline População Abastecida x Consumo per capita*** & 0,08 & 0,006 & Fraca \\
\hline Precipitação Pluviométrica x Consumo per capita* & 0,12 & 0,01 & Fraca \\
\hline
\end{tabular}

Os dados de algumas séries temporais foram reduzidos em função da indisponibilidade de informações, como segue: * 2003 a 2006 ; **2003 a 2007; $\mathrm{e}^{* * *} 2000$ a 2007.

Tabela 11 - Relação entre as variáveis determinando os coeficientes de correlação e a determinação para classificá-los de acordo com o grau de correlação.

Com base na Tabela 11, nota-se que a variável interveniente "Umidade relativa do ar média anual" apresentou um forte grau de correlação (associação positiva). Esse resultado difere de outros estudos, pois o de Yassuda et al. (1976) e Silva et al. (2008) destacam que essa variável apresenta influência, isto é, em regiões mais secas, onde a umidade relativa do ar é baixa, há aumento de consumo de água. Neste sentido, o grau de correlação encontrado por esses autores indica uma dependência linear inversa ou uma associação negativa. Portanto, pode-se concluir que a referida variável, pelo menos no período analisado, não apresenta resultado válido capaz de explicar o consumo de água.

$\mathrm{Na}$ sequência aparecem, respectivamente, a "Taxa média de água" e a "População total", que também apresentaram um forte grau de correlação, o que corrobora com os estudos de Yassuda et al. (1976). Ainda destaca-se que a variável interveniente "Temperatura média anual" apresentou um regular grau de correlação, diferentemente do estudo de Silva, et al. (2008), que não encontraram correlação quanto a esse aspecto; e, por fim, a "População abastecida" e a "Precipitação pluviométrica" apresentaram fraco grau de correlação.

Essas informações, comparadas ao estudo de Von Sperling et al. (2002) - realizado em 45 municípios do estado de Minas Gerais, por meio do qual concluíram que no consumo per capita existia a influência da precipitação pluviométrica e do porte da comunidade, e que este está relacionado com a população total - concordam quanto à influência da variável "População total", mas as demais variáveis encontradas diferem entre os estudos. Conclui-se que para cada região existem diferentes tipos de variáveis intervenientes e em graus de correlação diferenciadas. Não se pode, portanto, generalizar as variáveis por estados, mas sim, por localidades. 
Resultados e discussões: etapa da previsão futura

As funções identificadas pela modelagem matemática com a ajuda do software LAB Fit Ajuste de Curvas estão apresentadas na Tabela 12. Essas funções foram selecionadas tendo como parâmetro: qui-quadrado reduzido $\left(\mathrm{x}^{2}\right.$ red.); qui-quadrado $\left(\mathrm{x}^{2}\right)$; qui-quadrado crítico ( $\mathrm{x}^{2}$ crítico); graus de liberdade (gl); coeficiente de correlação (r); e o coeficiente de determinação $\left(\mathrm{r}^{2}\right)$ (Tabela 13).

Todas as funções da Tabela 12 apresentaram, conforme a Tabela 13, valores de $\mathrm{x}^{2}$ menores que o valor $\mathrm{x}^{2}$ crítico para um nível de significância de 5\%, observado os valores do gl, isto significa que as previsões das séries temporais em relação às funções não foram rejeitadas, ou seja, o erro entre a previsão da série temporal histórica não foi suficientemente grande para rejeitar as funções da Tabela 12. Portanto, aliando esta informação ao coeficiente $r$, que indica a confiabilidade da previsão da série temporal se ajustar à série temporal histórica, e ao coeficiente $r^{2}$, que indica a precisão do ajuste, concluiu-se que essas funções podem ser utilizadas para realizar a previsão futura.

Verificou-se ainda na Tabela 13 que as variáveis (Tempo, População Total, Consumo de água), com base na função número 382 (Tabela 12), apresentaram um coeficiente de $\mathrm{r}$ e $\mathrm{r}^{2}$ muito forte. Neste caso, pode-se afirmar que o crescimento do consumo de água pode decorrer do crescimento da população total.

A previsão do volume de água consumida (Tempo, Consumo de Água), função 33 da Tabela 12, para o ano de 2032 foi de 10,4 milhões de $\mathrm{m}^{3}$ e a previsão do volume de água consumida (Tempo, População Total, Consumo de Água) pela função 382 da Tabela 12 para o ano de 2032 foi de 10,6 milhões de $\mathrm{m}^{3}$. Portanto, verificou-se que, apesar da utilização de variáveis e funções diferentes na previsão da água consumida, houve uma variação insignificante entre as duas previsões.

$\mathrm{Na}$ realização da previsão do período de 2008 a 2032 do volume de água bruta captada, água tratada produzida, e água consumida utilizou-se, respectivamente, as funções de números 9 , 9 e 382 (Tabela 12) e o resultado foi apresentado na Figura 2.

Comparando-se os resultados da Figura 2 com o volume da vazão média e máxima do SAA da CORSAN de Lajeado/RS, notou-se que a vazão média de água (6,3 milhões $\mathrm{de}^{3}$ ) foi ultrapassada no ano de 2010, e a vazão máxima (9,3 milhões $\left.\mathrm{m}^{3}\right)$ será atingida no ano de 2026. Portanto, em meados desse ano, pela previsão realizada neste estudo, o abastecimento de água do SAA da CORSAN de Lajeado/ RS estará operando em seu limite máximo, ou seja, caso aumente o consumo por qualquer motivo, o abastecimento excedente deste con-

\begin{tabular}{|c|c|}
\hline Variáveis $(x, y)$ e $(x, x, y)$ & Identificação das funções \\
\hline (Tempo, Água Bruta Captada) & $\begin{array}{c}y=\frac{A}{X^{2}}+B \text {, onde } \\
A=-.7134 \mathrm{E}+15 \text { e } B=0.1832 \mathrm{E}+09\end{array}$ \\
\hline (Tempo, Água Tradada Produzida) & $\begin{array}{c}y=\frac{A}{X^{2}}+B, \text { onde } \\
A=-.7598 \mathrm{E}+15 \text { e } B=0.1943 \mathrm{E}+09\end{array}$ \\
\hline (Tempo, Consumo de Água) & $\begin{array}{c}\text { (33) } y=A+\frac{B}{X}+\frac{C}{X^{2}}, \text { onde } \\
A=0.2790 \mathrm{E}+11, B=-.1115 \mathrm{E}-15 \text { e } C=0.1114 \mathrm{E}+18\end{array}$ \\
\hline (Tempo, População Total) & $\begin{array}{c}(140) y=A \cdot e^{\frac{(X-B)^{2}}{C}}+D, \text { onde } \\
A=0.7907 \mathrm{E}+06, B=0.2075 \mathrm{E}+04, C=-.1042 \mathrm{E}+04 \text { e } D=0.5839 \mathrm{E}+05\end{array}$ \\
\hline (Tempo, População Total, Consumo de Água) & $\begin{array}{c}(382) y=A \cdot X_{1}^{3}+B . X_{2}^{2}+C . X_{1}+D . X_{2}, \text { onde } \\
A=0.3200 \mathrm{E}+01, B=-.1278 \mathrm{E}+05, C=0.1277 \mathrm{E}+08 \text { e } D=0.3092 \mathrm{E}+01\end{array}$ \\
\hline
\end{tabular}

Tabela 12 - Identificação das funções através do software LAB Fit Ajuste de Curvas para previsão das variáveis no período de 2008 a 2032. 


\begin{tabular}{l|c|c|c|l|l|}
\multicolumn{1}{c|}{ Variáveis $(x, y)$ ou $(x, x, y)$} & Função & $x^{2}$ & gl & $r$ & $r^{2}$ \\
\hline (Tempo, Água Bruta Captada) & 9 & 6 & 6 & 0,88 & 0,77 \\
\hline (Tempo, Água Tradada Produzida) & 9 & 6 & 6 & 0,93 & 0,87 \\
\hline (Tempo, Consumo de Água) & 33 & 5 & 5 & 0,99 & 0,98 \\
\hline (Tempo, População Total) & 140 & 4 & 4 & 0,86 & 0,75 \\
\hline (Tempo, População Total, Consumo de Água) & 382 & 4 & 4 & 0,99 & 0,98 \\
\hline
\end{tabular}

Obs.: Todas as funções apresentam $o x^{2}$ red. igual a 1.

Tabela 13 - Resultado dos parâmetros utilizados pelas funções da Tabela 12 na previsão do período de 2008 a 2032.

sumo será prejudicado. Neste caso, sugere-se que o SAA adote medidas estratégicas antes dessa data. As estratégias podem estar ligadas ao aumento da sua estrutura física para gerar maior vazão, uma reeducação da população para um consumo mais consciente, ou ainda a utilização de equipamentos domésticos mais eficientes no consumo de água.

\section{Conclusão geral: etapa da caracteriza- ção e da previsão}

O crescimento do volume de água bruta captada de 2000 a 2007 foi de 16,29\% e o volume de água tratada produzida foi de $23,96 \%$. Nota-se, na comparação histórica desses volumes, que há uma diminuição da variação do volume de água, pois verificou-se maior eficiência no tratamento da água e na limpeza da ETA nesse período.

O volume de água consumida teve um crescimento, de 2000 a 2007, de $20,45 \%$ e as perdas de água na rede de distribuição cresceram em $29,10 \%$, sendo a média da perda de água no período de 43,75\%. Notou-se que o crescimento do volume de água tratada produzida é maior que o crescimento do volume de água consumida, e isto se deve em função do aumento das perdas, pois quanto maior as perdas maior deve ser o volume de água tratada produzida para suprir o mesmo volume de água consumida.

A extensão da rede de distribuição no período

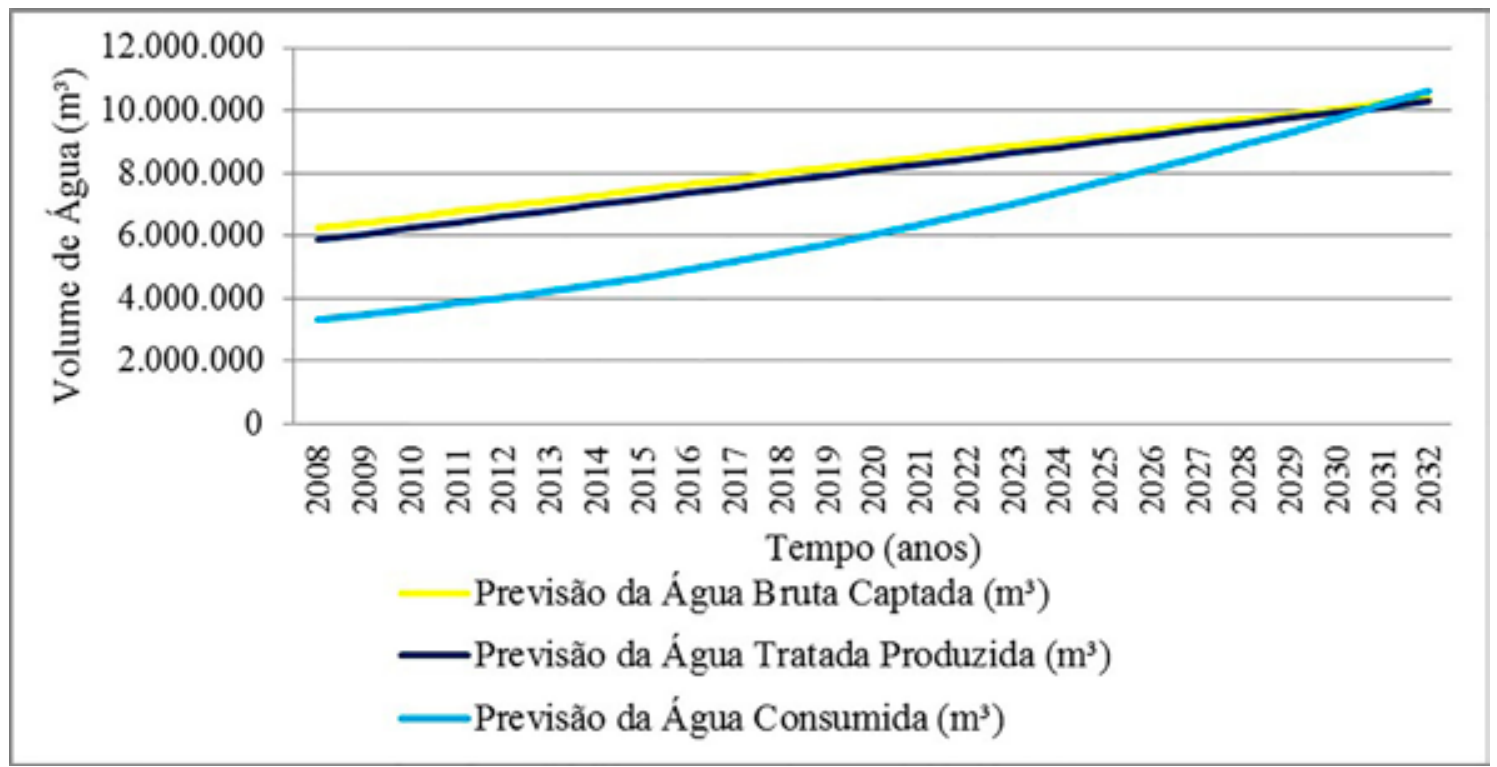

Figura 2 - A previsão da água bruta captada, da água tratada produzida e da água consumida de 2008 a 2032. 
de 2001 a 2007 foi ampliada em 8,53\%, equivalente a uma extensão de $20 \mathrm{~km}$, e a quantidade de ligações que tiveram um crescimento de $20,36 \%$, equivalentes a 2.480 ligações.

A população total teve um crescimento no período de 2000 a 2007 de $5,21 \%$, a população atendida cresceu 13,96\% e a população não atendida decresceu em 23,80\%. Portanto, notou-se que com a ampliação da rede de distribuição, também aumentou a população atendida e, consequentemente, reduziu a população não atendida. Cabe destacar que no decréscimo da população não atendida também teve a participação de SAA particulares da cidade de Lajeado e que não fizerem parte do escopo deste estudo.

O consumo per capita médio do período de 2000 a 2007 foi de 143,25 L/hab.dia e houve, no mesmo período, um crescimento de 5,55\%. O consumo per capita de 2007 foi de $152 \mathrm{~L} /$ hab.dia e através de sua decomposição em setores obteve-se o resultado: a) setor residencial $(84 \%)$; b) setor comercial $(13 \%)$; c) setor público (2\%) e d) setor industrial (1\%). Portanto, a elevada participação do setor residencial como consumidor per capita é devido à característica da cidade de Lajeado/RS ser essencialmente urbana, e das indústrias localizadas nesta cidade possuírem poços particulares para captação de água, o que explica que o setor industrial possui a menor participação.

As variáveis intervenientes que influenciam no consumo per capita desse SAA com forte grau de correlação são: a umidade relativa do ar; a taxa média de água; e a população total. A variável interveniente "Temperatura média anual" apresenta grau de correlação regular; a "População abastecida" e a "Precipitação pluviométrica" apresentam grau de correlação fraca. Portanto, o volume de consumo per capita de água do SAA de Lajeado/RS é influenciado pela umidade relativa do ar, pela taxa média de água e pela população total.

As funções utilizadas para realizar a previsão via modelagem matemática através do software LAB Fit Ajuste de Curvas do período de 2008 a 2032 foram: a água bruta em função do tempo (9); a água tratada produzida em função do tempo (9); o consumo de água em função do tempo (33); a população total em função do tempo (140); e o consumo de água em função do tempo e da população total
(382). Essas funções foram as que tiveram os melhores valores de qui-quadrado reduzido $\left(\mathrm{x}^{2}\right.$ red.), qui-quadrado $\left(x^{2}\right)$, qui-quadrado crítico $\left(\mathrm{x}^{2}\right.$ crítico), graus de liberdade (gl), coeficiente de correlação $(r)$ e o coeficiente de determinação $\left(\mathrm{r}^{2}\right)$.

A previsão da extrapolação do volume da vazão média (Figura 2) que ocorreu a partir de 2010 não é preocupante, pois à medida que faltar água para o consumo, o volume de água tradada produzida pode ser aumentado, visto que o volume da vazão máxima de água tratada produzida comporta até 9,3 milhões de $\mathrm{m}^{3}$. Portanto, o colapso por escassez de água no SAA da CORSAN de Lajeado (RS) em relação às variáveis analisadas ocorrerá em meados de 2026 (Figura 2). Recomenda-se aumentar a estrutura deste SAA antes de 2026, uma vez que, nesse ano, o SAA estará com a capacidade de vazão máxima de água tratada produzida.

É recomendável que o aumento deste SAA seja projetado bem antes de 2026, pois qualquer mudança no cenário, como mudança na cultura da população atendida, clima, taxas, etc., pode acarretar a antecipação da falta de estrutura suficiente para produção de água tratada produzida. Neste caso, é necessário rever a previsão.

Ao comparar os volumes previstos de água tradada produzida e do consumo de água para o ano de 2008 com os dados efetivos realizados pelo SAA da CORSAN de Lajeado (RS) verificou-se que a diferença entre os dados não foi superior a um desvio padrão de $2.000 \mathrm{~m}^{3}$ / ano. Considerando o volume total de água consumida num ano, a diferença é insignificante. Portanto, as variáveis projetadas correspondem aos valores reais, o que confere credibilidade e confiabilidade à previsão através do software LAB Fit Ajuste de Curvas.

\section{REFERÊNCIAS}

AMARAL, A.M.P. e SHIROTA, R. Consumo residencial médio de água tratada: uma aplicação de modelos de séries temporais em Piracicaba. Revista Agrícola, v. 49, n. 1, p. 55-72, 2000.

AYRES, M.C.R. Sistema de abastecimento de água potável no município de Dourados/MS: caracterização de análises. 78 f. Dissertação (Mestrado Agronomia - Energia na Agricul- 
tura) - Universidade Est. Paulista Júlio Mesquita Filho, Botucatu, 2000.

BASSANEZI, R.C. Ensino-Aprendizagem com Modelagem Matemática. 3. ed. São Paulo: Contexto, 2006.

BDR- Banco de Dados Regional da Univates. Disponível em: <http://www.bdr.univates.br>. Acesso em: 07 mar. 2009.

CALLEGARI-JAQUES, S.M. Bioestatística: princípios e aplicações. 1. ed. Porto Alegre: Artmed, 2003.

CIH - Centro de Informações Hidrometeorológicas. Disponível em: http://www.univates.br/ servicos/centro-de-informacoes-hidrometeorologicas. Acesso em: 21 mar. 2009.

CLARKE, R. e KING, J. $\mathrm{O}$ atlas da água: O mapeamento completo do recurso mais precioso do planeta. 1. ed. São Paulo: Publifolha, 2005.

CORSAN- Companhia Rio-grandense de Saneamento. Disponível em: <http://www.corsan. com.br>. Acesso em: 25 jan. 2009.

DIAS, D.M.; MARTINEZ, C.B e LIBANIO, M. Avaliação do impacto da variação da renda no consumo domiciliar de água. Eng. Sanit. Ambient. vol.15, n.2, p. 155-166. 2010.

FALKENBERG, A. V. Previsão de consumo urbano de água em curto prazo. 2005. $85 \mathrm{f}$. Dissertação (Mestrado em Métodos Numéricos em Engenharia) - Universidade Federal do Paraná, Curitiba-PR, 2005.

FERNANDES NETO, M.L. Avaliação de parâmetros intervenientes no consumo per capita de água: estudo para 96 municípios do estado de minas gerais. 146 f. Dissertação (Mestrado em Saneamento, Meio Ambiente e Recursos Hídricos) - Escola de Engenharia da Universidade Federal de Minas Gerais, Belo Horizonte, 2003.

FERNANDES NETO, M.L.; NAGHETTINI, M.; Von SPERLING, M. e LIBÂNIO, M. Avaliação da relevância dos parâmetros intervenientes no consumo per capita de água para os municípios de Minas Gerais. Revista ABES, v. 9, n. 2, p. 100-107, 2004.
HERRERA, O.M. Caracterização e análise do sistema de abastecimento de água potável no município de Botucatu, SP. 100 f. Dissertação (Mestrado Agronomia - Energia na Agricultura) - Universidade Estadual Paulista Júlio Mesquita Filho, Botucatu, 1996.

IBGE - Instituto Brasileiro de Geografia e Estatística. In: Síntese de Indicadores Sociais - Uma Análise das Condições de Vida da População Brasileira. Rio de Janeiro, 2008. Disponível em: <http://www.ibge.gov.br/home/ estatistica/populacao/condicaodevida/indicadoresminimos/sinteseindicsociais2008/indic sociais2008.pdf > Acesso em: 15 jan. 2009.

LEVINE, D. M.; STEPHAN, D.; KREHBIEL, T. C. e BERENSON, M. L. Estatística - Teoria e aplicação usando o Microsoft ${ }^{\circledR}$ Excel em português. $3^{\mathrm{a}}$ ed. Rio de Janeiro: LTC, 2005.

MAGALHÃES, C.A.C.; MORENO, J. e GALVÃO, A.C.G. Estimativa do consumo per capita em comunidades atendidas pela unidade de negócio do médio Tietê. In: Congresso Brasileiro de Engenharia Sanitária e Ambiental, 21, João Pessoa. Anais eletrônicos do $21^{\circ}$ Congresso da ABES. Rio de Janeiro: ABES, 2001. Disponível em: <http://www.bvsde.paho.org/bvsaidis/ caliagua/brasil/i-061.pdf> Acesso em: 25 fev. 2008.

MOTTA, V. T. Bioestatística. $2^{\mathrm{a}}$ ed. Caxias do Sul, RS: Educs, 2006.

NARCHI, H. A demanda doméstica de água. Revista Dae. São Paulo, ano 5, n. 154, p. 01- 07, 1989.

NUCCI, N. L. R. Avaliação da demanda urbana de água. Aspectos econômicos e urbanísticos. A área edificada como possível explicativa e prospectiva. Revista Dae. São Paulo, ano 4, n. 135, p. 22 - 29, 1983.

PERH-MS - Plano estadual de recursos hídricos de Mato Grosso do Sul. Campo Grande, MS: Editora UEMS. 194 p. ISBN: 978-85-9988024-1. 2010

PITTOCK, J. A crise da água atinge também os países ricos. Revista Eco 21. Ed. 118, set. 
2006.

PML - Prefeitura Municipal de Lajeado/RS. Disponível em: <http://www.lajeado-rs.com. $\mathrm{br} /$ internas.php?conteudo=infra_abastec. php> Acesso em: 28 Jan. 2009.

QUEIROZ, A.T. e OLIVEIRA, L.A. Relação entre produção e demanda hídrica na bacia do rio Uberabinha, estado de Minas Gerais, Brasil. Soc. nat., vol.25, n.1, p. 191-204, 2013.

ROCHA, W.S. e SILVA, R.T. Caracterização da demanda urbana de água: Programa Nacional de Combate ao Desperdício de Água (PNCDA). Documento técnico de apoio - Presidência da República Secretaria Especial de Desenvolvimento Urbano Secretaria de Política Urbana, p. 49, 1999.

SÃO PAULO (Estado). Relatório de Situação dos Recursos Hídricos do Estado de São Paulo. São Paulo, 2007: Disponível em: <http:// www.comitepcj.sp.gov.br/download/RS/

RSESP2007_03Tiete.pdf> Acesso em: 17 jul. 2013.

SILVA, W.T.P. Modelagem aplicada à determinação da quota per capita de água: um instrumental para gestão de recursos hídricos no município de Cuiabá. 58 f. Dissertação (Mestrado em Ciências Florestais e Ambientais) - Universidade Federal de Mato Grosso, Cuiabá-MT, 2008.

SILVA, W.P.; SILVA, C.M.D.P.S.; CAVALCANTI, C.G.B.; SILVA, D.D.P.S.; SOARES, I. B.; OLIVEIRA, J.A.S. e SILVA, C.D.P.S. "LAB Fit ajuste de curvas": um software em português para tratamento de dados experimentais. Rev. Bras. Ens. Fis., vol.26, n.4, p.419-427, 2004.

SILVA, W. T. P.; SILVA, L. M. e CHICHORRO, J.F. Gestão de recursos hídricos: perspectivas do consumo per capita de água em Cuiabá. Eng. Sanit. Ambient. vol.13, n.1, p. 8-14. 2008.

SNIS - Sistema Nacional de Informações Sanitárias. Disponível em: <http://www.snis.gov. br>. Acesso em: 01 set. 2009.

SNIS - Sistema Nacional de Informações Sanitárias. Disponível em: <http://www.snis.gov. br> Acesso em: 08 dez. 2011.

TRAUTWEIN, J. B. Avaliação de métodos para avaliação de previsão de consumo de água para curtíssimo prazo: um estudo de caso em empresa de saneamento. 107 f. Dissertação (Mestrado). Pontifícia Universidade Católica do Paraná, Curitiba. 2004.

TUNDISI, J.G. Recursos hídricos no futuro: problemas e soluções. Estudos Avançados, vol.22, n.63, p. 7-16. 2008.

VON SPERLING, M. Principio de tratamento biológico de águas residuárias. 2 ed. Belo Horizonte: DESA-UFMG, 1996.

VON SPERLING, M.; SANTOS, A.S.P.; MELO, M.C. e LIBÂNIO, M. Investigação de fatores de influência no consumo per capita de água em estados brasileiros e em cidades de Minas Gerais. In: VI Simpósio Ítalo Brasileiro de Engenharia Sanitária e Ambiental (SIBESA), 2002, Vitória. Anais... Vitória, 2002.

WEBSTER, A.L. Estatística aplicada à Administração e Economia. 1 ed. São Paulo: McGraw-Hill, 2006.

WITTE, R.S.; WITTE, J.S. Estatística. 7. ed. Rio de Janeiro: LTC, 2005.

WOLMAN, A. Havia regras sobre "Água Pura" há 4.000 anos atrás. Revista Dae. São Paulo, ano 1, n. 34, p. 93-94, 1959.

YASSUDA E.R.; OLIVEIRA W.E.; GAGLIANONES.; NOGAMI P.S.; PEREIRA B.E.B. e MARTINS J. A. Técnica de abastecimento e tratamento de água - vol. 1. 2a. ed. São Paulo: CETESB, 1976. 
